\title{
Estimation of the Effects of Food on the Pharmacokinetic Results in Bioequivalence Studies
}

\author{
ION MIRCIOIU ${ }^{1}$, VALENTINA ANUTA2*, CONSTANTIN MIRCIOIU², VICTOR VOICU², ROXANA SANDULOVICI ${ }^{1}$ \\ IUniversity Titu Maiorescu, Faculty of Pharmacy, 16 Gheorghe Sincai Blvd., 040317, Bucharest, Romania \\ 2University of Medicine \& Pharmacy Carol Davila, Faculty of Pharmacy, 6 Traian Vuia Str., 020956, Bucharest, Romania
}

\begin{abstract}
Paper presents the effect of food on the pharmacokinetics of omeprazole and on the extraction yield of its internal standard, lansoprazole. The experimental data were obtained over three bioequivalence studies performed by the authors. Statistical analysis of plasma level curves of omeprazole indicated that food induces a delay of the time of maximum concentrations, but had a lower effecton maximum concentration and area under curves. Peak areas of lansoprazole were not constant, presenting a similar pattern in all seven periods of the clinical experiment, both in feeding and fasting conditions: an increase after the standard meal at four hours from the administration of drug followed by relatively constant, buthigher areas afterwards. Statistical analysis of data (1500 points) in the 3- $6 \mathrm{~h}$ interval, i.e. from immediately before until two hours after food intake revealed a two phase effect: an initial decrease of areas followed by an increase to a higher level than in the preprandial conditions, leading to the appearance of a minimum in curves one hour after food intake. In almost all cases a good parabolic fitting of data was obtained, which is in agreement with authors previous results on extraction of ketoconazole from pasma in methylene chloride in the presence of bile salts. The increase of peak areas of lansoprazole from two hours after meal by $24 \mathrm{~h}$ lead to an artificial decrease of calculated omeprazole concentrations. This effect could explain the unexpected lack of food effect on the area under curve of omeprazole, observed in the comparison between areas in fasting and fed conditions.
\end{abstract}

Keywords: omeprazole, ketoconazole, methylene chloride

For immediate-release drug products belonging to Biopharmaceutical Classification System Class II (high permeability, low solubility), III (low permeability, high solubility) and IV (low permeability, low solubility) as well as for all modified-release drug products, food intake significantly impacts the in vivo release and absorption of the active components. Consequently, for these drugs, the Guidance for Industry, Food-Effect Bioavailability and Fed Bioequivalence Studies recommend to test bioavailability (BA) and bioequivalence (BE) in both fasting and fed conditions.

For the fed BE studies, a standard high-fat meal is provided 30 minutes before drug administration, with no food intake allowed for at least $4 \mathrm{~h}$ post-dose.

Both fasting and fed studies last at least twelve hours and, in this time interval subjects receive two meals, usually at four hours and nine hours after drug administration.

The food intake induces bile discharging into the duodenum. Bile salts [BS], resulted from hepatic metabolism of cholesterol, [1] are stored in the gall bladder are later reabsorbed from the terminal ileum, and reach back the liver via the portal vein [2]. The hepatic extraction can reach even $90 \%$ and usually remains constant during the fasting state and during digestion [3,4]. Consequently, a significant more or less periodical variation of $\mathrm{BS}$ concentrations into the blood and intestinal fluid occurs. Concentrations in blood are lower than $5 \mu \mathrm{M}$ in fasting conditions an increase in postprandial conditions up to 15 $\mu \mathrm{M}[5,6]$.

Bile salts form micelles aggregates that play an important role in the gastrointestinal digestion and absorption of lipids [7-9] and of lipophilic substances, particularly drugs [10]. The micelles of bile salt have low aggregation numbers, typically 2-10 units [11,12].

Mixed micelles formed by association with phospholipids are larger and have greater solubilizing capacity which is particular important in the case of lipophilic drugs [13-15].

Bile acids and bile salts play a critical role in lipid assimilation by promoting emulsification [4] and being responsible for postprandial lipemia. Effect of bile salts on absorption of active substances is reflected in almost all pharmacokinetic parameters: maximum concentration, time of maximum concentration and area under curve [16].

The effects of food and bile salts on pharmacokinetics are extensively studied, being a special chapter in documentation for authorization of drugs .

\section{Postprandial plasma}

The effect of food intake on plasma properties is clearly visible to the naked eye. Morning plasma, usually after a ten hours fasting interval has a clear aspect whereas postprandial plasma appears like a milky emulsion.

All the above aspects are particularly important in the analytical evaluation of plasma levels during pharmacokinetic studies and could, at least partially, be included in a vast research domain of bioanalytics called matrix food effect. The procedures for validation of bioanalytical methods recommended by the European Medicines Agency Guidance [17] take into consideration such effects, but mainly when using mass spectrometry detection techniques, known to be particularly susceptible to matrix effects $[18,19]$. It is how ever expected that other bioanalitycal methods to also be influenced by plasma content, but their study was less considered by researchers.

In order to reduce the variability of food effects, in BE studies the standardization of food and water intake during the entire period when subjects remain in the clinical facility is compulsory. But standard meal virtues are jeopartized by the fact that subjects are not standardized and, after a such meal some remains hungry, some are satiated and

*email:vali_anuta@yahoo.com 
this state could influence the results more than a food ad libitum.

\section{Estimation of food effects in bioequivalence and in dissolution studies}

In the case of generic drugs, pharmacokinetic studies are not required and are restricted following ethic considerations [20], a good alternative being to valuate data from bioequivalence studies undertaken as surrogate of clinical trials for testing therapeutic equivalence [21]. Once again and under the same pressure of ethics committees, some bioequivalence studies are replaced with in vitro dissolution studies in biorelevant media, i.e. media simulating intestinal content in feeding and in fasting conditions [22,23], by controlling the $\mathrm{pH}$, osmolarity, buffer capacity, butespecially by addition of bile salts and lecithin

Even more simplified models of food effects are obtained by the study of the release kinetics of active substances from drug products in media containing non-physiological surface active agents. These simplified models are validated by correlation with in vivo pharmacokinetics data obtained in fasting and fed conditions [24].

A most generic approach of food effect evaluation undertaken by the authors was to study of the impact of different concentrations of BS, lecithin and their mixture on the extraction yield of a low solubility compound (ketoconazole) from plasma in methylene chloride [25].

Present paper reports the effect of food on pharmacokinetics of omeprazole and the statistical analysis of the measured peak areas of the internal standard lansoprazole added to plasma before extraction of the active substance, throughout three bioequivalence studies performed in our laboratory: two in fasting conditions and another one in both fasting and fed conditions.

\section{Experimental part \\ Methods \\ Clinical studies}

The clinical studies investigated the bioequivalence ofthe test products, generic gastrorezistant capsules containing $20 \mathrm{mg}$ omeprazole and the reference product (LOSEC ${ }^{\circledR} 20 \mathrm{mg}$, ASTRA ZENECA, gastrorezistant capsules containing $20 \mathrm{mg}$ omeprazole), comparing the rate and extent of absorption of omeprazole after a single $40 \mathrm{mg}$ oral dose, on fast state. Studies were designed as standard two sequences, two periods, crossover studies, analytically blinded.

In each study 36 healthy male and female caucasian volunteers, aged between 18 and 50 years and with a body mass index between 19 and 25 were enrolled. In order to study omeprazole pharmacokinetics under fed conditions, a third period was added to one of the studies,

Blood samples $(5 \mathrm{~mL})$ were collected before dosing $(0.0 \mathrm{~h})$ and $0.5,1.0,1.5,2.0,2.5,3.0,3.5,4.0,5.0,6.0,7.0$, 8.0, 10.0 and 12.0 after drug administration, ( 15 samples). The volunteers remained fasted for at leastten hours before drug administration, in the first two periods of the clinical study. Standard meals were provided at four and ten hours after drug administration. Cuantification of omeprazole plasma concentrations was performed using a validated HPLC method. The plasma treatment involved addition of the internal standard (lansoprazole), followed by liquid/ liquid extraction of the analytes into methylene chloride. All sample preparation steps were performed in a light protected environment.

The chromatographic separation was achieved on a Hypersil Gold, $5 \mu \mathrm{m} 150 \times 4 \mathrm{~mm}$ column (Thermo Fisher Scientific, Waltham, MA, USA), using a $0.0125 \mathrm{M}$ phosphate buffer solution $(p H=6)$ : acetonitrile isocratic mixture $(68: 32 \mathrm{v} / \mathrm{v})$ as mobile phase. The eluent was monitored at $302 \mathrm{~nm}$.

The linearity assessment was performed using a 7 point calibration curve in the range $0.025-2.5 \mu \mathrm{g} / \mathrm{mL}$ The injection volume was $100 \mu \mathrm{L}$.

\section{Results and discussions}

Total food effect on pharmacokinetics of Omeprazole

As can be seen in figure 1 , the mean curves of omeprazole plasma levels emphasised a very important food effect in terms of the time of maximum concentration (tmax), which was increased with by hours in fed conditions, whereas the calculated effects (table 1) reveal that maximum concentrations $\left(C_{\max }\right)$ and areas under curves (AUC) were less influenced.

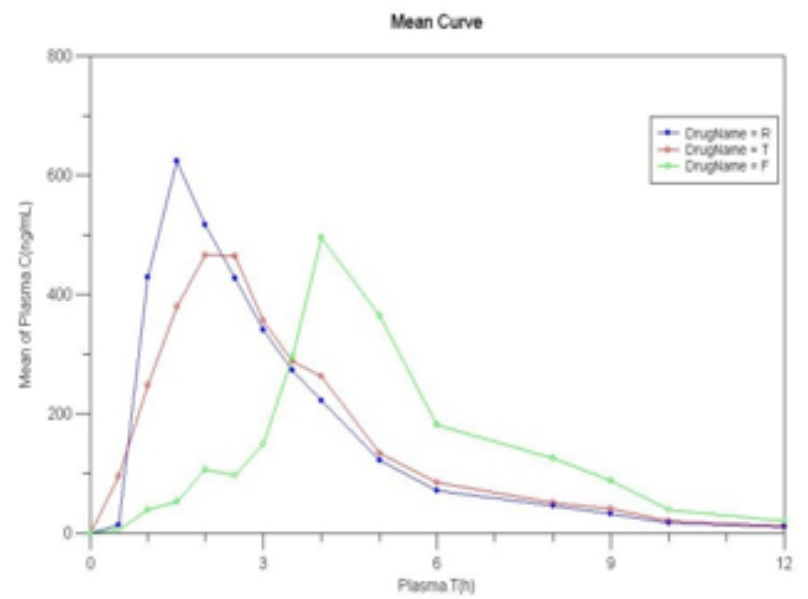

Fig. 1. Mean plasma levels of omeprazole: reference in fasting state $(R)$, tested in fasting $(T)$ and fed $(F)$ state

Table 1

COMPARISON OF PHARMACOKINETICS OF OMEPRAZOLE IN FASTING AND FED CONDITIONS

\begin{tabular}{|c|c|c|c|c|c|c|}
\hline Drug Name & & $\begin{array}{c}\mathrm{C}_{\max } \\
(\mathrm{ng} / \mathrm{mL})\end{array}$ & $\begin{array}{c}\mathrm{t}_{\max } \\
(\mathrm{h})\end{array}$ & $\begin{array}{c}\mathrm{t}_{\text {half }} \\
(\mathrm{h})\end{array}$ & $\begin{array}{c}\mathrm{AUC}_{0-\pi} \\
\left(\mathrm{ng} / \mathrm{mL}^{*} \mathrm{~h}\right)\end{array}$ & $\begin{array}{c}\mathbf{A U C}_{0-\mathbf{m}} \\
\left(\mathrm{ng} / \mathrm{mL}^{*} \mathrm{~h}\right)\end{array}$ \\
\hline \multirow{2}{*}{ Tested product - FAST state: } & Mean & 689 & 2.17 & 1.57 & 1742 & 1800 \\
\cline { 2 - 8 } & $\% \mathrm{CV}$ & 61.93 & 38.67 & 90.28 & 103.69 & 109.29 \\
\hline \multirow{2}{*}{ Tested product - FED state: } & $\mathrm{Mean}$ & 641 & 3.92 & 1.32 & 1719 & 1806 \\
\cline { 2 - 8 } & $\% \mathrm{CV}$ & 72.53 & 36.37 & 55.26 & 107.32 & 113.27 \\
\hline
\end{tabular}

\begin{tabular}{|c|c|c|c|c|}
\hline Variable & Point estimate (\%) & $90 \%$ Confidence Interval & ANOVA CV (\%) & Table 2 \\
\hline $\mathrm{C}_{\max }(\mathrm{ng} / \mathrm{mL})$ & 94.89 & $81.32-110.71$ & 38.6 & STATE - PRIMARY VARIABLES FOR \\
\hline $\operatorname{AUC}_{0-\boldsymbol{m}}\left(\mathrm{ng} / \mathrm{mL}^{*} \mathrm{~h}\right)$ & 102.71 & $92.16-114.47$ & 24.8 & \\
\hline
\end{tabular}



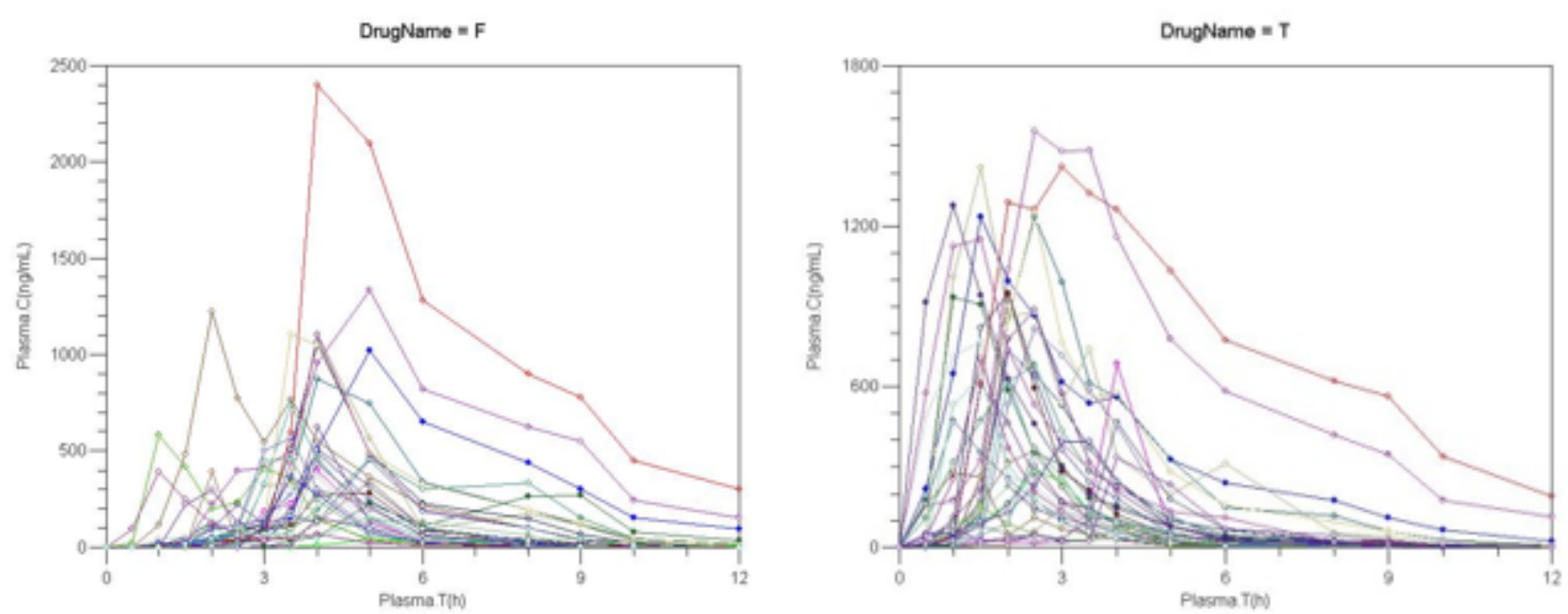

Fig. 2. Individual plasma levels of omeprazole concentration in fed $(F)$ and fasting $(T)$ conditions

Table 1 and table 2 confirm the visual observations related to significant $t_{\text {max }}$ differences, and additionally reveals another significant aspect -the huge variability of all parameters. Particularly, both partial and total AUCS have a coefficient of variation of more that $100 \%$.

Highly variable pharmacokinetics in both fasting and fed conditions is more obvious after examination of the clusters of plasma level curves presented in figure 2. Variability is huge in terms of $\mathrm{C}_{\text {max }} t_{\text {max }}$ and AUC.

In the fed conditions study appeared in addition an outlier subject, additionaly increasing the variability. However, in bioequivalence studies despite proposals, it is not yet permitted to discard outliers [26] .

\section{Effect on extraction from plasma}

It was further attempted to separately estimate the effects on analytical results following the modifications of plasma content induced by food intake, by comparing the measurements of the peak of internal standard (lansoprazole).

The modifications induced by food intake on plasma were obvious even to the naked eye, with its overall appearence changing from a clear liquid to milky-like emulsion.

Areas of lansoprazole peaks for 36 subjects (two periods cummulated) of experiment in the $3-6 \mathrm{~h}$ interval are presented in figure 3.

Since the meal was supplied at four hours after drug administration, the estimation of the effects of plasma modifications on the extraction yield of lansoprazole,the samples obtained from 3 to $6 \mathrm{~h}$ after drug administration were used. Examination of the 72 curves set revealed that

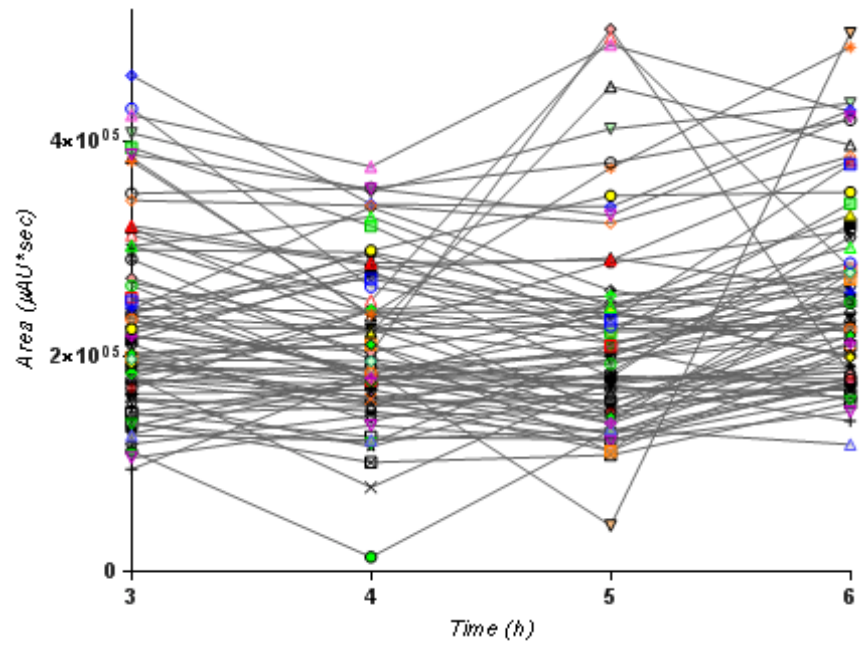

Fig. 3. Areas of lansoprazole in both periods of a same BE study, in the $3-6 \mathrm{~h}$ interval almost all curves present a minimum at $5 \mathrm{~h}$. Some ten curves have the minimum at $4 \mathrm{~h}$, while four are presenting a rather outlier behaviour, with a maximum at five hours,

In a global evaluation, it can be seen that with the exception of two curves, the other 70 areas are decreasing immediately after the meal intake, in the 4 - $5 \mathrm{~h}$ interval, and increase afterwards in the $5-6 \mathrm{~h}$ interval. The two outliers had a minimum at $4 \mathrm{~h}$ and a maximum at $5 \mathrm{~h}$.

Mean curves of lansoprazole plasma levels in the 0 - 12 $\mathrm{h}$ interval for seven periods of studies ( six in fasting conditions and one in fed conditions) are presented in figure 4.

Evaluation of the curves in the $0-12 \mathrm{~h}$ interval suggests that there are two domains of approximetely constant areas - one before $4-5 \mathrm{~h}$ interval and one from approximately $6 \mathrm{~h}$ onwards. Postprandial areas look to be higher than the preprandial ones. This trend concerns mainly the experiments in fasting state but, as can be seen in figure 5 in case of the experiment with three periods, a minimum in the $4-5 \mathrm{~h}$ interval was also observed in fed conditions.

For a better illustration of the food effect the mean curves in the different periods of all selected studies are represented in figure 6 . It can be observed that practically in all cases, in the neghbourhood of the food intake time a small decrease in mean areas appeared, followed by anincrease to a higher than the preprandial values. As can be seen in the figure 6 , the total mean for 245 curves (Pool Av) clearly presents the trend suggested from the evaluation of the mean curves in all seven periods.

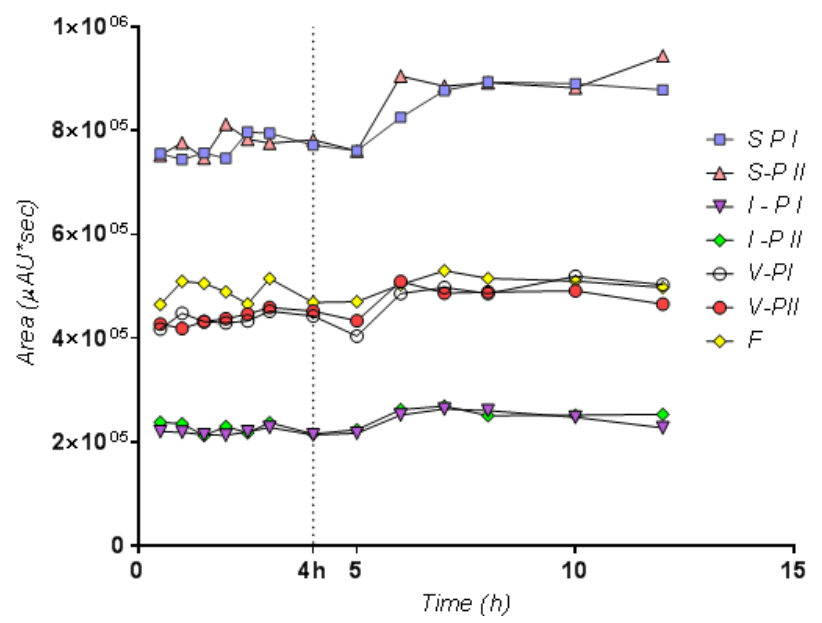

Fig. 4. Mean curves of lansoprazole plasma levels in the $0-12 \mathrm{~h}$ interval for seven phases of studies designed in figure by $\mathrm{S}, \mathrm{I}$ and $\mathrm{V}$, and fed conditions study by $\mathrm{F}$ 


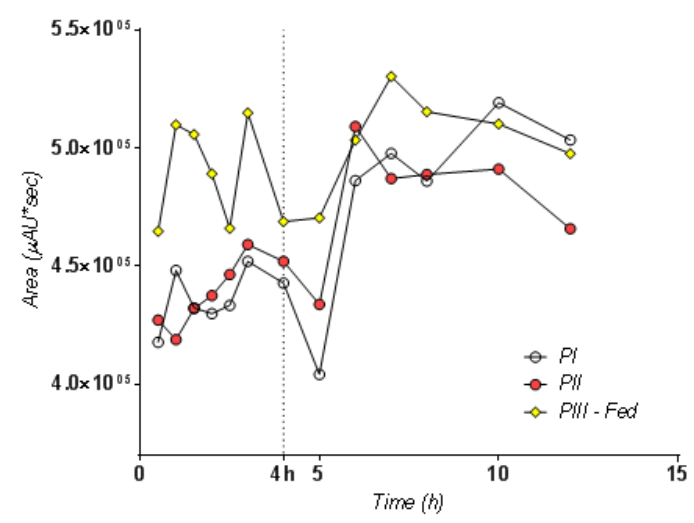

Fig. 5. Peak areas of Lansoprazole in the three periods of the study $\mathrm{V}$
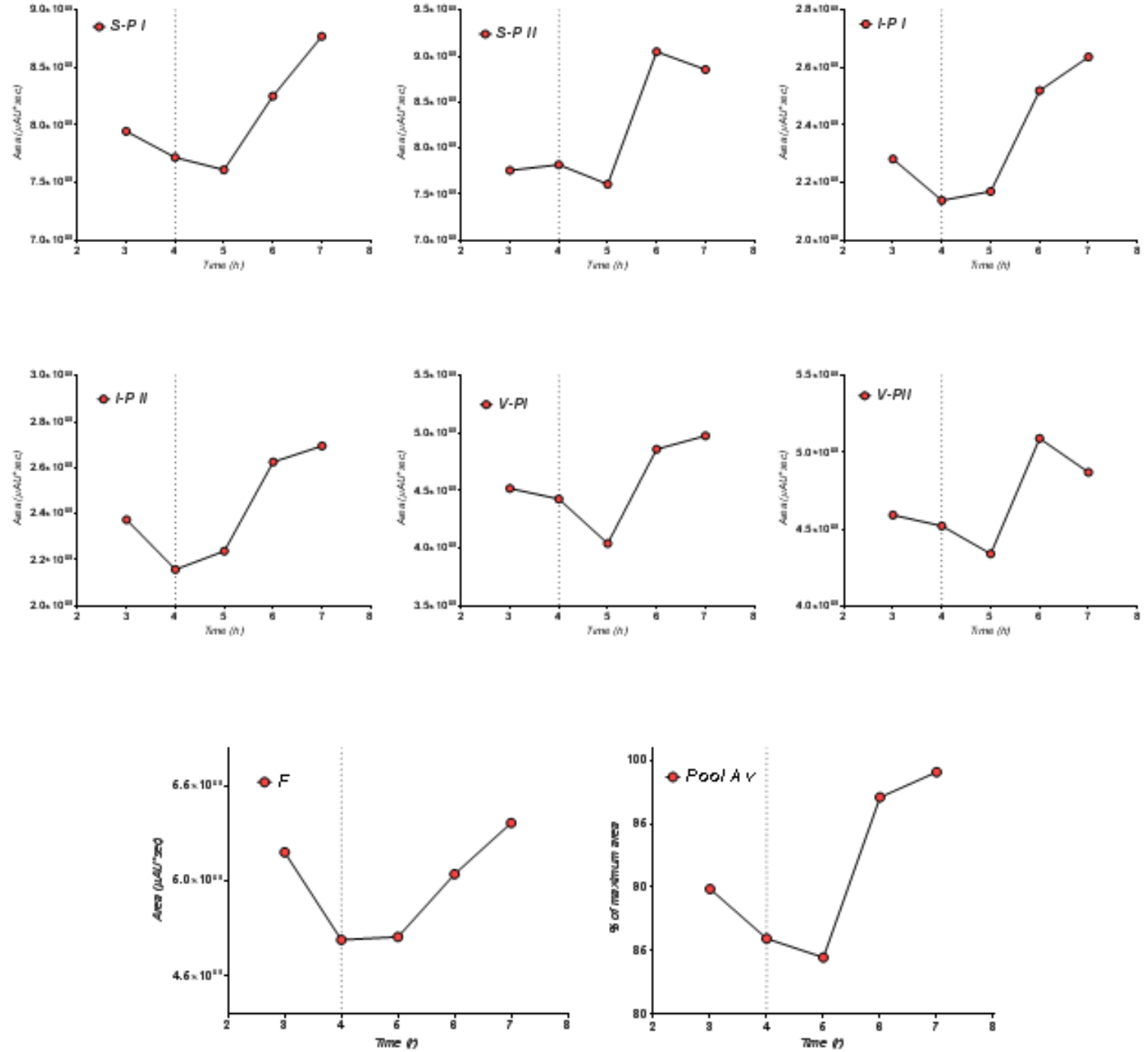

Fig. 6. Mean curves in the $3-6 \mathrm{~h}$ interval, corresponding to seven periods of the clinical studies. Because of the differences in scale of the internal standard areas between studies, the pooled average (PoolAv) was calculated by mediating the areas from the seven periods, expressed as percent of the maximum area in the respective study.

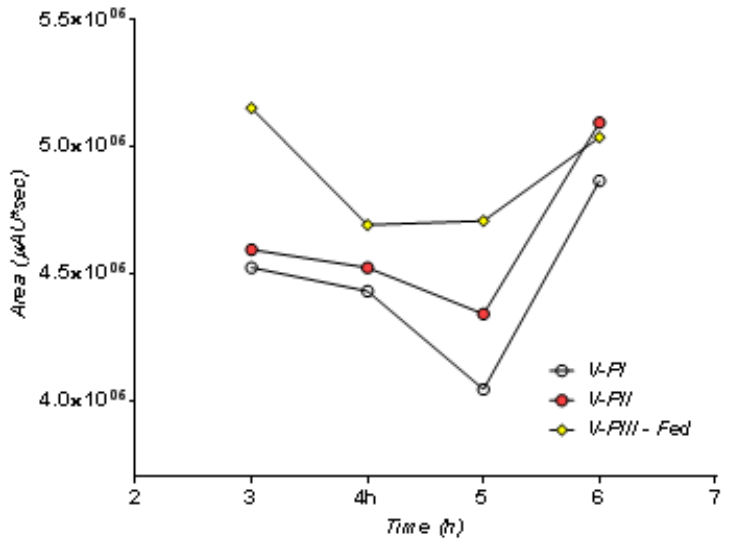

Fig. 7. Peak areas in the $3-6 \mathrm{~h}$ interval in study $\mathrm{V}$, in fasting and fed conditions 
The effects of food on bioavailability

Omeprazole has a partition coefficient $\log P=2.33$ [27], and therefore high solubility in lipids. Therefore, in the case of fed studies, entrapment of the active substance in the lipids from the high fat standard meal given to subjects prior to drug administration, leads to a delay in the absorption and an increase of $t_{\text {ax }}$. This effect was very obvious the case in our $V$ study, $t_{\max }$ increasing from approximately two to four hours.

After food intake, following the secretion of bile salts, lipids are emulsified and their absorption is expected to promote increase of the concentrations in plasma and of AUC in case of lipophilic active substances. As can be seen in table 1 , this was not the case in our study. $C_{\text {max }}$ had a small decrease and there were no significant differences in the $A \cup C_{0-24}$ and $A \cup C_{0 .+}$ between fasting and fed conditions. Similar results were reported in literature [28].

In fact, as was recognized even from beginning of its use in therapy, absorption of omeprazole from its entericcoated formulation is unpredictable[29]. As observed in figures 2 and 3 and in table 1, plasma level curves, both in fasting and fed conditions are highly variable. There are some causes of this variability. Firstly, omeprazole is highly unstable in acidic conditions and the gastrorezistent protective film for granules does notensure $100 \%$ protection of the active compound from the gastric environment. The second cause is the fact that omeprazole is completely metabolized by the cytochrome P450 system, mainly in the liver. Identified metabolites are the sulfone, the sulfide, and hydroxy-omeprazole. About $80 \%$ of an orally given dose is excreted as metabolites in the urine, and the remainder is found in the feces, primarily originating from bile secretion [30]. For subjects extensive and poor metabolizers, AUC and $C_{\text {max }}$ are very different [31].

Delay in absorption can also be considered following a physiologically motivated time-delay induced by enterohepatic circulation of bile salts [32].

Last but not least, a reason for variability is the fact that food intake modify the extraction yield of omeprazole from postprandial plasma in methylene chloride,conclusion supported by the trends observed in the time evolution of the measured levels of lansoprazole $(\log P=2.76)$ that was used as internal standard and therefore was identically added to all plasma samples.

In a previoius paper [25] authors estimated the effect of postprandial changes in human plasma on analytical results in methods which included liquid/liquid extraction. Experiments concerned extraction from plasma samples in methylene chloride in presence of sodium taurocholate bile salt (BS), lecithin $(\mathrm{L})$ or their mixture within the therapeutic range of ketoconazole $(\mathrm{K})$.

The effect of lecithin on ketoconazole extraction was not linear but rather parabolic. At high analyte concentrations, the dependence between BS concentration and ketoconazole extraction yield was also found to be parabolic. The enrichment of plasma with both $B S$ and $L$ led to a similar behaviour i.e. a parabolic evolution of $K$ extraction as a function of $B S+L$ mixture concentration being obtained. In one of studies here reported (I) parabolic fitting of the lansoprazole peak areas proved to be very succesful (fig. 8).

The process of distribution of lansoprazole during postprandial plasma samples preparation is complex, involving several distributions:

- transfer from plasma in methylene chloride,

- transfer from plasma in different micelles of BS as well in mixed micelles of bile salts with lecithin,

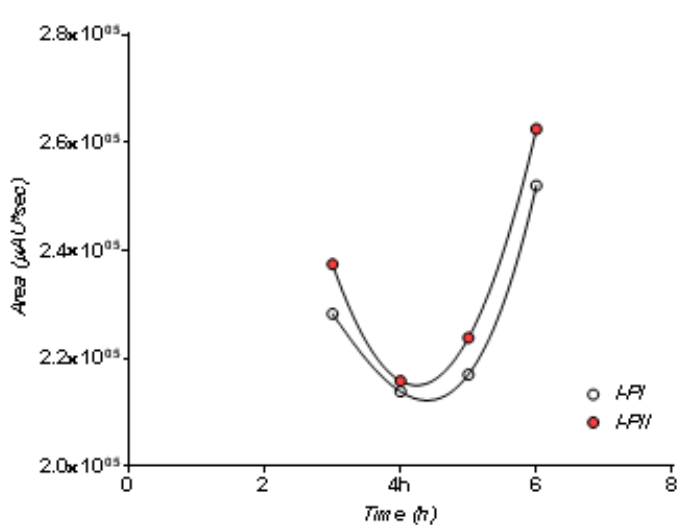

Fig. 8. Parabolic regression of time dependence of lansoprazole peak area in the around the time of food intake

- transfer in and from lipid emulsions or multiple emulsions or liposomes, leading to equilibria determined by partition coefficients

$$
C_{p}=C_{p}^{f}+k_{o / m} C_{m}^{p} C_{o}=C_{o}^{f}+k_{o / m} C_{m}^{\circ} C_{p}^{f} / C_{o}^{f}=k_{p / 0}
$$

where:

$C_{o}^{f}$ is the concentration of free lansoprazole in organic phase, $C_{p}^{f}$ is concentration of free lansoprazole in plasma, $k_{o / m}$ is the partition coefficient between the organic phase and micelles and $C_{m}$ is the concentration of micelles.

Other critical phenomena could be associated with the critical micellar concentrations (CMC) of the bile salts and lecithin. The mean of the CMC values for the egg-yolk lecithin fractions was found $15.3 \mathrm{mg} / \mathrm{mL}$ and that for soybean lecithin was $15.8 \mathrm{mg} / \mathrm{mL}$ [33] i.e. of the same order with their concentration in plasma [34].

Finally, since concentrations of omeprazole were calculated from the ratio between areas of omeprazole peak and area of lansoprazole peak, an increase of peak areas of lansoprazole after five hours point led to an artificial decrease of omeprazole concentration. Maybe this effect could explain the unexpected lack of effect on the AUC omeprazole observed in comparison between AUCs in fasting and feeding conditions.

\section{Conclusions}

Food intake produced a drastic change of plasma samples aspect from a clear liquid to a milky like emulsion.

Modification of experimental conditions from fasting to a high fat feeding on pharmacokinetics results in a bioequivalence study concerning omeprazole formulations led to a significant delay of the time of maximum concentration $t_{\text {max }}$ from two hours to four hours. Effects on maximum concentration and area under curves were much lower than expected and not statistically significant, due to high variability of results.

Time course of lansoprazole internal standard mean peak areas was similar in all seven periods of experiments (some 1500 points): an initial decrease of areas around time of food intake, followed by an increase to a higher level than in the preprandial conditions. 4. In almost cases a good parabolic fitting of lansoprazole time course evolution around the time of fook intake was obtained which is in agreement with authors published data on extraction of ketoconazole from pasma in methylene chloride in presence of bile salts.

Increase of peak areas of lansoprazole from two hours after meal by 24 hours lead to an artificial decrease of omeprazole concentration. This effect could explain the unexpected lack of effect on the AUC omeprazole observed in comparison between AUCs in fasting and feeding conditions. 


\section{References}

1. MONTE, M.J., MARIN, J.G., ANTELO, A.J., World J. Gastroenterol, 15, no. 7, 2009, p. 804.

2. HOUTEN, S.M., AUWERX, J., Ann. Med., 36, no. 7, 2004, p. 482.

3. STREET, J.M., TRAFFORD, D.J., MAKIN, H.L., J. Lipid. Res., 24, no. 5, 1983, p. 491.

4. HOFMANN. A.F., Biochem. J., 89, 1963, p. 57.

5. ENGELKING, L.R., DASHER, C.A., HIRSCHOWITZ, B.I., Am. J. Clin. Pathol., 73, no. 2, 1980, p. 196.

6. EVERSON, G.T., J. Lipid. Res., 28, no. 3, 1987, p. 238.

7. CAREY, M.C., SMALL, D.M., Arch. Intern. Med., 130, no. 4, 1972, p. 506.

8. LUNER, P.E., J. Pharm. Sci., 82, no. 3, 1993, p. 311.

9. BORGSTROM, B., J. Lipid. Res., 8, no. 6, 1967, p. 598.

10. DE SMIDT, J.H., OFFRINGA, J.C., CROMMELIN, D.J ., J. Pharm. Sci.,

80, no. 4, 1991, p. 399.

11. CAREY, M.C., SMALL, D.M., Am. J. Med., 49, 1970, p. 590.

12. CAREY, M.C., Hepatology, 4, no. 5 Suppl,, 1984, p. $138 \mathrm{~S}$.

13. IMAI, J., HAYASHI, M., AWAZU, S., HANANO, M., Chem. Pharm. Bull. (Tokyo), 31, no. 11, 1983, p. 4077.

14. NIGHTINGALE, C.H., WYNN, R.J ., GIBALDI, M., J. Pharm. Sci., 58, no. 8, 1969, p. 1005.

15. NOOK, T., DOELKER E., BURI, P., Pharm. Acta. Helv., 62, no. 10-11, 1987, p. 274.

16. CHRENOVA, J., DURISOVA, M., MIRCIOIU, C., DEDIK, L., Methods Find Exp. Clin. Pharmacol, 32, no. 6, 2010, p. 413.

17. *** EMEA/CHMP/EWP/192217/2009. Guideline on bioanalytical method validation. http://www ema europa eu /docs/ en GB/ document_library/ Scientific_guideline/ 2011/08/WC500109686 pdf.

18. MATUSZ̄EWSKI, B.K., CONSTANZER, M.L., CHAVEZ-ENG, C.M., Anal. Chem., 75, no. 13, 2003, p. 3019.

19. CHAMBERS, E., WAGROWSKI-DIEHL, D.M., LU, Z., MAZZEO, J.R., J. Chromatogr. B. Analyt. Technol. Biomed Life Sci., 852, no. 1-2, 2007, p. 22.

20. MANOLACHE, M., CADAR, E., ANTONESCU, D., MIRCIOIU, C., PRASACU, I., SANDULOVICI, R., Journal of Science and Arts, 1, 2018, p. 239.
21. GHERGHICEANU, F., SANDULOVICI, R., PRASACU, I., ANUTA, V., MIRCIOIU, C., Farmacia, 64, no. 6, 2016, p. 823.

22. PREDA, I., MIRCIOIU, I., MIRCIOIU, C., CORLAN, G., PAHOMI, G., PRASACU, I., ANUTA, V., Farmacia, 60, no. 5, 2012, p. 675.

23. MIRCIOIU, I., ANUTA, V., IBRAHIM, N., MIRCIOIU, C., Farmacia, 69, no.3, 2012, p. 315.

24. MIRCIOIU, I., ANUTA, V., PURCARU, S.O., RADULESCU, F., MIRON, D., DUMITRESCU, I.B., IBRAHIM, N., MIRCIOIU, C., Farmacia, 61 , no. 1, 2013, p. 88.

25. PAHOMI. G. , CORLAN, G., ANUTA, V., SANDULOVICI, R., MIRCIOIU, I., Farmacia, 60, no. 6, 2012, p. 809.

26. MIRCIOIU, C., IONICA, G., DANILCEAC, A., MIRON, D., MIRCIOIU, I., RADULESCU, F., Farmacia, 58, no. 3, 2010, p. 264.

27. SANGSTER, J., LOGKOW Databank. Montreal Quebec, Canada: Sangster Res. Lab. (1994).

28. PILLAI, G.K., HASSAN, M.M., SALEM, M., NAJ IB, N.M., International J ournal of Pharmaceutical Medicine, 12, no. 4, 1998, p. 199.

29. HOWDEN, C.W., MEREDITH, P.A., FORREST, J.A.H., REID, J.L., European Journal of Clinical Pharmacology, 26, no. 5, 1984, p. 641.

30. Santarus Inc. Zegerid (omeprazole/sodium bicarbonate) capsules and powder for oral suspension prescribing information. FDA drug label, https://www.accessdata.fda.gov/drugsatfda_docs/label/2010/ 021636s008lbl.pdf .

31. UNO, T., NIIOKA, T., HAYAKARI, M., YASUI-FURUKORI, N., SUGAWARA, K., TATEISHI, T., European Journal of Clinical Pharmacology, 2007, 63, no. 2, 2007, p. 143.

32. TVRDONOVA, M., DEDIK, L., MIRCIOIU, C., et al., Basic \& Clinical Pharmacology \& Toxicology, 104, no. 1, 2009, p. 35.

33. PALACIOS, L.E., WANG, T., J. Am Oil Chem. Soc., 2005, 85, no. 1, 2005, p. 371.

34. CAREY, MC., Bile acids in Gastroenterology. Lancaster: MTP Press,1983, p. 19.

Manuscript received: 13.12 .2018 